\title{
DESVENDANDO AS RELAÇÕES DE OUTRAS DISCIPLINAS COM A PRODUÇÃO CIENTÍFICA DA CIÊNCIA DA INFORMAÇẨO BRASILEIRA
}

\section{UNVEILING THE RELATIONSHIPS OF OTHER DISCIPLINES WITH THE SCIENTIFIC PRODUCTION OF BRAZILIAN INFORMATION SCIENCE}

\author{
Wesley Rodrigo Fernandesa \\ Beatriz Valadares Cendón ${ }^{b}$
}

\begin{abstract}
RESUMO
Introdução: Apesar da ciência da informação ser rotulada como uma ciência interdisciplinar a literatura demonstra que não há um consenso na comunidade científica sobre essa questão. Objetivos: Investigar na literatura científica o uso do conhecimento produzido pela ciência da informação nacional por pesquisadores das demais áreas científicas e determinar o tipo de relação (multi, inter ou transdisciplinar) estabelecida entre as outras disciplinas e a ciência da informação. Metodologia: A pesquisa foi realizada em duas etapas. Os dados analisados na primeira etapa foram provenientes de uma análise de citações a trabalhos da ciência da informação brasileira publicados entre 1997 e 2016 e presentes na SciELO. Na segunda etapa foi realizada análise quantitativa em uma amostra não probabilística por conveniência de $15 \%$ das citações de outras disciplinas a trabalhos oriundos da ciência da informação nacional identificados na primeira etapa. Ainda na amostra utilizada na segunda etapa, para os trabalhos das citações que apresentaram propriedades indicativas de serem construídos a base de uma relação interdisciplinar foi realizada uma análise qualitativa para determinar o tipo de relação disciplinar estabelecida nesses trabalhos. Resultados: Destaca-se que foi observada uma tendência de crescimento das citações dos trabalhos nacionais da área de ciência da informação pelas demais áreas do conhecimento científico. Foi verificado também que as demais áreas do conhecimento utilizam do conhecimento científico produzido pela ciência da informação nacional. Conclusões: Verificou-se que a ciência da informação nacional parece ter avançado teórica e metodologicamente de modo sistemático nesses últimos 20 anos. Também observou-se a indicação de ocorrência de uma potencial relação interdisciplinar de outras disciplinas com a ciência da informação brasileira. Entretanto esta potencial relação interdisciplinar não foi confirmada pela análise quanti-qualitativa realizada na segunda etapa da pesquisa.
\end{abstract}

a Doutor em Gestão e Organização do Conhecimento pela Universidade Federal de Minas Gerais (UFMG). Bibliotecário da Faculdade de Letras da Universidade Federal de Minas Gerais (UFMG). E-mail: wesleyronline@yahoo.com.br.

b Doutora em Ciência da Informação pela University of Texas at Austin. Docente do Programa de Pós-Graduação em Gestão \& Organização do Conhecimento da Universidade Federal de Minas Gerais (UFMG). E-mail: bcendon@gmail.com. 
Descritores: Ciência da informação. Interdisciplinaridade. Multidisciplinaridade. Transdisciplinaridade. Epistemologia da ciência da informação.

\section{INTRODUÇÃO}

Desde o seu surgimento, a ciência da informação $(\mathrm{Cl})$ foi rotulada como uma ciência interdisciplinar. Os primeiros conceitos, definições e debates acerca do novo campo já o anunciavam com essa característica (CROSLAND, 1962; TAYLOR, 1966; BORkO, 1968; SHERA; CLEVELAND, 1977).

Ao longo dos anos outros autores nacionais e internacionais também enxergaram a área como interdisciplinar (SARACEVIC, 1996; PINHEIRO; LOUREIRO, 1995; PINHEIRO, 2006; MORAES; CARELLI, 2016).

Por outro lado, encontra-se na literatura algumas pesquisas que questionam o discurso afirmatório da característica interdisciplinar do campo ou até mesmo refutam por completo a existência dessa característica (PAIM, 2001; GOMES, 2001; BICALHO, 2009; HIGINO; DUMONT, 2012; SANTANA, 2012, SANTOS NETO et al., 2017).

Alguns trabalhos desta segunda corrente apontam que a $\mathrm{Cl}$ busca muito mais teorias, conceitos e metodologias nas disciplinas com as quais tem alguma relação do que fornece a elas teorias, conceitos e metodologias levando ao questionamento da interdisciplinaridade da área e à sugestão de que se analise também se há algum movimento dessas outras disciplinas em direção à Cl numa perspectiva de integração de conhecimentos de maneira a propiciar um enriquecimento mútuo entre as disciplinas envolvidas.

A respeito das pesquisas sobre a interdisciplinaridade na $\mathrm{Cl}$ Gomes (2001, f. 5-6) propõe que:

É preciso identificar as disciplinas que vêm de fato promovendo alterações em seus campos teórico-práticos a partir da incorporação dos resultados e teses produzidas no interior da ciência da informação, como também promovendo seus profissionais e pesquisadores à luz desse referencial, efetuando o que efetivamente pode ser compreendido como um diálogo interdisciplinar (GOMES, 2001, f. 5-6).

Outro trabalho a propor que se analise os movimentos de outras disciplinas em direção à $\mathrm{Cl}$ numa perspectiva de integração de conhecimentos e 
enriquecimento mutuo das disciplinas foi Santos Neto et. al. (2017). De acordo com os autores:

Se a interdisciplinaridade exige que haja cooperação mútua entre as áreas e apropriação de saberes construídos conjuntamente, é necessário um outro olhar sobre esses estudos, ou seja, é necessário verificar como se dá a ocorrência de citação de autores da $\mathrm{Cl}$ nas áreas recorrentemente citadas no âmbito da $\mathrm{Cl}$, como a Administração, a Computação, etc. Visto que a interdisciplinaridade se caracteriza pela "[...] intensidade das trocas realizadas entre os cientistas especializados e o grau de integração real das disciplinas [...]" (BICALHO; OLIVEIRA, 2011), assim, é fundamental verificar essa integração nas demais disciplinas que contribuem para o corpus da $\mathrm{Cl}$, e não somente no contexto dela própria. A análise deve ser realizada além das fronteiras da $\mathrm{Cl}$, no intuito de descobrir quais disciplinas têm incorporado conhecimento dessa área à sua de origem (SANTOS NETO et al., 2017, p. 29).

Fica evidente que essas pesquisas que questionam o discurso afirmatório da interdisciplinaridade na $\mathrm{Cl}$ contestam a metodologia utilizada em várias delas, que apenas avaliam a utilização pela $\mathrm{Cl}$ do conhecimento de outras disciplinas, sem efetivamente avaliar se essa utilização é promovida através de um relacionamento consciente entre as disciplinas, de forma a propiciar uma reciprocidade nas trocas de modo que todas as partes envolvidas sejam transformadas, requisitos básicos para a ocorrência de uma pesquisa interdisciplinar.

Em meio à divergência de entendimentos demonstrada nas pesquisas que se preocuparam em estudar a interdisciplinaridade na $\mathrm{Cl}$ e a verificação de escassez de estudos que avaliem se as disciplinas recorrentemente listadas como as que promovem um diálogo interdisciplinar com a $\mathrm{Cl}$ também utilizam do conhecimento produzido pela área de forma a propiciar uma integração de teorias e metodologias e uma interlocução de pesquisas e pesquisadores que promovam um enriquecimento mútuo entre as disciplinas envolvidas, surgem algumas questões levantadas neste artigo. Será que outras áreas científicas se utilizam do conhecimento produzido na $\mathrm{Cl}$ nacional para subsidiarem a construção de seus campos teórico, prático e metodológico? Se sim, quais seriam essas áreas? Está essa utilização promovendo uma pesquisa interdisciplinar com o campo? 
Este estudo teve como objetivo geral investigar, na literatura científica, o uso do conhecimento produzido pela $\mathrm{Cl}$ nacional por pesquisadores das demais áreas científicas, para darem sustentação teórica, metodológica ou conceitual às suas pesquisas e se esse uso se concretiza numa perspectiva de integração de teorias e metodologias bem como de interlocução de pesquisas e pesquisadores de modo a propiciar um enriquecimento mútuo entre as partes envolvidas. Os objetivos secundários foram: 1 - identificar quais áreas recorrem às descobertas da $\mathrm{Cl}$ nacional para discutirem sobre suas inquietações/problemas; e 2 - verificar o nível de relação/interação disciplinar (multi, inter ou transdisciplinar) estabelecido entre as outras áreas do conhecimento com a Cl brasileira.

\section{A QUESTÃO DA INTERDISCIPLINARIDADE NA CIÊNCIA DA INFORMAÇÃO}

Para uma melhor compreensão dessa pesquisa, apresentam-se primeiramente os elementos comuns ou características básicas que norteiam o entendimento dos termos multidisciplinaridade, interdisciplinaridade $\mathrm{e}$ transdisciplinaridade e foram adotados como bases conceituais para esses termos nesse trabalho.

Os tipos de interação pluridisciplinar e multidisciplinar foram tratados como um por representarem uma forma mínima de relação disciplinar (POMBO, 2008), ou pelo fato da diferença entre os dois termos ser mínima, fato explicado apenas pela "maior ou menor aproximação ou "afinidade" entre as disciplinas que estão interagindo" (BICALHO, 2009, p. 78). Em ambas perspectivas não há a ocorrência de integração mútua entre os conhecimentos das respectivas disciplinas envolvidas, na qual geralmente nenhuma disciplina sai enriquecida, ou apenas uma (JANTSCH, 1972; PIAGET, 1972; JAPIASSU, 1976; DOMINGUES, 2005; REPKO, 2012).

Os elementos comuns e características básicas que norteiam 0 entendimento da interdisciplinaridade nessa pesquisa adotados pelos autores Jantsch (1972); Piaget (1972); Japiassu (1976); Pombo (2004); Repko (2008). são: 
$1^{0}$ - Relação de duas ou mais disciplinas distintas (entenda-se disciplina como área do conhecimento) que se relacionam de forma consciente para atingir um objetivo comum;

2o - Há reciprocidade nas trocas de modo que todas as disciplinas envolvidas são transformadas epistemologicamente, metodologicamente ou teoricamente;

$3^{\circ}$ - Produz um avanço cognitivo no entendimento da temática estudada a partir da interação, conversão e integração dos conhecimentos das disciplinas que estão se relacionando para esse objetivo;

$4^{\circ}$ - A interdisciplinaridade não rompe com as disciplinas, ela apenas aproxima disciplinas distintas para em interação fornecer respostas mais "inteiras", "concertadas", "abrangentes" e "alargadas" a desafios complexos.

No que diz respeito a transdisciplinaridade, ela seria o nível mais elevado nas relações disciplinares. Porém as atuais estruturas das comunidades científicas, dos regimes pedagógicos e das escolas ainda não permitem que esse nível aconteça em sua plenitude, ou seja, um sistema de relações disciplinares sem fronteiras estáveis entre as disciplinas (uma vez que o transdisciplinar se preocupa com o conhecimento produzido entre as disciplinas, através das disciplinas e além das disciplinas), com níveis e objetivos múltiplos coordenando todas as disciplinas em busca de uma finalidade comum ou uma teoria global, ou seja, a pesquisa transdisciplinar ainda seria uma utopia (JANTSCH, 1972; PIAGET, 1972; POMBO, 2004; NICOLESCU, 2001).

Desde seu nascimento, a $\mathrm{Cl}$ já tinha um status de área interdisciplinar, como pode ser percebido nas palavras de Crosland (1962, p. 592), sua idealizadora nos Estados Unidos, ao dizer que, para enfrentar os problemas relacionados com o manuseio eficiente da informação técnica, era necessário a "combinação de insights de cientistas, engenheiros, bibliotecários, agentes de informação, matemáticos, especialistas em informática e linguístas".

A característica da relação da $\mathrm{Cl}$ com outras disciplinas pode ser observada na definição dada à área nas conferências do Georgia Tech:

ciência que investiga as propriedades e o comportamento da informação, as forças que governam o fluxo da informação e os meios de processar a informação para ótimo acesso e uso. $O$ 
processo inclui produção, disseminação, coleta, organização, armazenamento, recuperação, interpretação e uso da informação. O campo é derivado de, ou relacionado à matemática, lógica, linguística, psicologia, tecnologia computacional, pesquisa operacional, artes gráficas, comunicação, biblioteconomia, administração e outros campos similares (CROSLAND, 1962, p. 593, tradução e negrito nosso).

Borko (1968) escreveu um artigo que teve a finalidade de explicar o que era a área, o que fazia um cientista da informação e como tudo isso se relacionava com a biblioteconomia e a documentação. Em seu artigo, ele apresentou sua clássica definição sobre a $\mathrm{Cl}$ :

ciência que investiga as propriedades e o comportamento da informação, as forças que governam o fluxo da informação e os meios de processar a informação para ótimo acesso e uso. Está interessada num conjunto de conhecimentos relacionados com a produção, coleta, organização, armazenamento, recuperação, interpretação, transmissão, transformação e utilização da informação. Inclui a investigação das representações da informação nos sistemas naturais e artificiais, a utilização de códigos para transmissão eficiente da mensagem, o estudo de instrumentos e técnicas de processamento da informação, tais como computadores e seus sistemas de programação. É uma ciência interdisciplinar derivada de e relacionada com a matemática, a lógica, a linguística, a psicologia, a tecnologia computacional, a pesquisa operacional, as artes gráficas, as comunicações, a biblioteconomia, a administração e assuntos similares. Tem componentes de uma ciência pura, que investiga o assunto sem se preocupar com sua aplicação, e componentes de uma ciência aplicada, que cria serviços e produtos (BORKO, 1968 , p. 3, tradução e negrito nosso).

Observa-se que as duas definições apresentadas anteriormente são bem semelhantes, sendo a de Borko (1968) mais abrangente. Nela o autor deixa claro a questão da característica interdisciplinar da área, além de postular que a Cl é ciência pura e ciência aplicada ao mesmo tempo.

Saracevic (1996, p. 47), conceitua a Cl como sendo:

um campo dedicado às questões científicas e à prática profissional voltadas para os problemas da efetiva comunicação do conhecimento e de seus registros entre os seres humanos, no contexto social, institucional ou individual do uso e das necessidades de informação. No tratamento dessas questões são consideradas de particular interesse as vantagens das modernas tecnologias informacionais.

No mesmo trabalho, o autor estabelece três características básicas que constituem um modelo para a compreensão da área e dos problemas que ela 
enfrenta. A primeira dessas características é sua natureza interdisciplinar; a segunda, sua ligação direta com a tecnologia da informação; e a terceira, diz respeito à sua participação ativa e deliberada na evolução da sociedade da informação em conjunto com outras disciplinas.

Saracevic (1996) esclarece também que estas relações com outras disciplinas mudam constantemente e que esta evolução estaria distante de ser completada. De acordo com o autor, a interdisciplinaridade foi introduzida na $\mathrm{Cl}$ pela diversidade da formação de todas as pessoas que se preocuparam em resolver os problemas da área. Foram várias as áreas que estabeleceram alguma relação interdisciplinar com a $\mathrm{Cl}$, mas as mais significantes foram: biblioteconomia, ciência da computação, ciência cognitiva (incluindo inteligência artificial) e comunicação.

No início do século XXI, o pesquisador israelense Chain Zins buscou explorar os fundamentos teóricos do campo e elaborar um mapa do conhecimento da área que pudesse definir seu conceito. Zins investigou como o conceito da $\mathrm{Cl}$ era entendido por 57 líderes acadêmicos da área de 16 países diferentes. Ao final da pesquisa, 49 respondentes contribuíram com suas definições e reflexões demonstrando como cada um entendia a área e seu objeto de maneira muito particular e diversa e que, dessa forma, o conceito de $\mathrm{Cl}$ ainda estaria em constituição. Os resultados da pesquisa foram publicados em uma série de quatro artigos. (ZINS, 2007 a, b, c, d). Apesar de não ter chegado a uma definição consensual para a área, a característica interdisciplinar foi mencionada por vários autores, como reforça Nunes (2009, p. 41), ao destacar que "todas elas traduzem mais ou menos os mesmos princípios norteadores, sendo que os principais e mais utilizados foram os aspectos referentes à informação, à afirmação da interdisciplinaridade e à forte ligação com as tecnologias de informação". Esses princípios coincidem com as três características básicas da área relacionados por Saracevic (1996).

A característica interdisciplinar do campo, contudo, não é unanimidade entre os pesquisadores da área. Há correntes que até entendem que o campo apresente a característica, sob determinada visão, mas contestam as metodologias utilizadas nos estudos sobre o tema. Existem também outras 
correntes que defendem que o campo não seja interdisciplinar em sua prática científica.

Alguns pesquisadores (BRAGA, 1995; TARGINO,1995) apontam para uma ausência na $\mathrm{Cl}$ de um corpo de fundamentos teóricos que possam traçar o seu horizonte científico e essa ausência forçam seus pesquisadores a recorrerem a outras disciplinas para sustentar a própria área. Isso leva muitos pesquisadores a confundirem a busca unilateral por teorias, metodologias e conceitos como relações interdisciplinares.

Bicalho (2009, p. 232), observou essa questão ao discorrer que a característica conferida à área não é sustentada em sua prática de pesquisa, uma vez que, os "autores ao frequentarem sozinhos outras áreas do conhecimento buscam complementar conhecimentos teóricos ou procuram por metodologias de outras áreas que deem suporte à realização de suas pesquisas" sem que ocorra integração de teorias e metodologias, nem a interlocução entre pesquisadores que propiciem um enriquecimento mútuo de disciplinas e pessoas envolvidas, condição necessária, segundo a autora, para que um trabalho seja interdisciplinar.

Os resultados da pesquisa de Bicalho (2009) revelaram que a $\mathrm{Cl}$, reconhecida pela quase totalidade de seus pesquisadores como interdisciplinar, não reflete em sua pesquisa essa característica. Tal afirmação está apoiada no fato de que:

as pesquisas realizadas com participação de outras áreas, publicadas nos periódicos especializados estudados, em sua maioria, não apresentam a necessária integração de teoria e metodologias, nem a desejável interlocução entre pesquisadores para a promoção de enriquecimento mútuo de disciplinas e pessoas envolvidas na pesquisa. Os resultados da pesquisa apontam para a existência de pesquisa multidisciplinar (BICALHO, 2009, p. 242).

Souza (2011) também constatou que a $\mathrm{Cl}$, em decorrência da sua insuficiente maturidade disciplinar, constrói seus laços interdisciplinares de forma unidimensional, sem levar em conta a contribuição que a área tem dado às disciplinas com as quais supostamente mantém relações interdisciplinares. $O$ autor destaca ainda que as relações interdisciplinares são vinculadas a precisas definições disciplinares "e, nessa perspectiva, a ciência da informação necessita, 
em primeira instância, construir seu domínio teórico e metodológico de forma minimamente consolidada para atuar ativamente no processo interdisciplinar" (SOUZA, 2011, p. 278).

Gomes (2001) esclarece que, muitas vezes, confunde-se interdisciplinaridade com mera incorporação de conceitos, teorias e métodos de uma disciplina por outra. De acordo com a autora, um diálogo interdisciplinar ocorre "quando conceitos, teorias, métodos e campos de investigação migram, transitam nos vários sentidos das 'regiões fronteiriças' concretizando essa interdisciplinaridade", de modo que a $\mathrm{Cl}$ receba contribuições, mas também contribua para o universo do conhecimento das áreas de fronteira. A atividade interdisciplinar implica na modificação das disciplinas envolvidas.

De acordo com Paim et al. (2001), os estudiosos da Cl têm discutido a respeito do desenvolvimento epistemológico da área, por julgarem-no insatisfatório. $\mathrm{A} \mathrm{Cl}$ tem importado uma gama de conhecimentos de outros campos do saber, tendo, portanto, sido considerada pelos teóricos uma ciência interdisciplinar. No entanto, para as autoras o campo não tem praticado sua interdisciplinaridade, pois não ocorre "fertilização mútua de saberes" no processo de assimilação de conhecimentos de outras áreas. "O que acontece na prática é uma justaposição de conceitos das diversas disciplinas". (PAIM et al., 2001, p. 21)

Em uma recente pesquisa, Higino e Dumont (2012) analisaram o tema (interdisciplinaridade da $\mathrm{Cl}$ ) a partir de trabalhos publicados no Encontro Nacional de Pesquisa em Ciência da Informação (ENANCIB) entre 2003 e 2008.

$\mathrm{Na}$ análise interpretativa dos conteúdos argumentativos de todos estes trabalhos investigados foram "reveladas inconsistências, fragilidades e tensões, além de articulações entre discursos teóricos e ação político-institucional" (HIGINO; DUMONT, 2012, p. 1). Os principais problemas apontados foram: conceituais, teóricos ou metodológicos, mas também foram feitas críticas aos trabalhos no que se refere às conclusões, ao fato de os autores direcionarem resultados para aquilo em que já acreditavam, entre outras.

Souza (2015) questiona a forma como foi e ainda está sendo construído o pensamento interdisciplinar no campo, uma vez que todos os alicerces dessa 
construção como por exemplo: "a ciência da informação é interdisciplinar por natureza" ou "promovem sua relação com uma rede de disciplinas que compõem o conhecimento informacional", não incentivam a área a trabalhar com uma perspectiva interdisciplinar que promova a discussão de definição do domínio disciplinar.

Santos Neto et al. (2017, p. 29) alertam que é necessário um outro olhar sobre os estudos que se propõem a analisar a interdisciplinaridade na $\mathrm{Cl}$, "ou seja, é necessário verificar como se dá a ocorrência de citação de autores da $\mathrm{Cl}$ nas áreas recorrentemente citadas no âmbito da Cl", e se esse relacionamento está ocorrendo de forma integrativa.

Enfim, observa-se que a questão da interdisciplinaridade na $\mathrm{Cl}$ ainda tem um vasto campo de pesquisa, apesar de vários autores apresentados nessa revisão já considerarem a área interdisciplinar. Dentre os campos de pesquisa possíveis aponta-se a necessidade de investigar se o conhecimento produzido no campo da $\mathrm{Cl}$ é utilizado por outras disciplinas e caso verificada essa utilização, se esse relacionamento ocorre de maneira integrativa de modo a promover um enriquecimento mútuo entre as partes envolvidas, ou seja, de maneira interdisciplinar.

\section{METODOLOGIA}

Para se alcançar os objetivos propostos anteriormente os quais foram problematizados por Gomes (2001) e Santos Neto et al. (2017), de pesquisar não somente os movimentos que a $\mathrm{Cl}$ faz em direção às outras disciplinas, mas também de verificar se estas outras disciplinas fazem algum movimento em direção à $\mathrm{Cl}$ e se esses movimentos se concretizam numa perspectiva de integração, bem como os objetivos específicos, este artigo teve seu percurso metodológico dividido em duas etapas.

\subsection{Primeira Etapa}

Para identificar se há outras áreas que recorrem às descobertas da $\mathrm{Cl}$ para sanarem suas inquietações/problemas e quais são elas, esta pesquisa 
adotou como corpus de estudo os periódicos nacionais que se dedicam a publicar exclusivamente pesquisas realizadas dentro do escopo de interesse da área indexados na base Scientific Electronic Library Online (SciELO), que foi escolhida por permitir um melhor mapeamento das redes de citações em âmbito nacional e regional, em comparação com outras bases internacionais existentes, pelo fato desta base indexar uma quantidade maior de periódicos nacionais de todas as áreas do conhecimento, incluindo a área de $\mathrm{Cl}$, bem como periódicos da América Latina, Caribe, África do Sul e Portugal.

Hayashi et al. (2008, p. 185) explica que a SciELO "proporciona uma forma de garantir a visibilidade e a acessibilidade da literatura científica, além de espelhar a produção científica brasileira na internet".

Para a avaliação do uso do conhecimento produzido pela $\mathrm{Cl}$ nacional por pesquisadores das demais áreas científicas nos periódicos nacionais investigados foi elaborada uma análise retrospectiva dos anos de 1997 até 2016, a qual possibilitou traçar um panorama histórico-evolutivo da interação de outras disciplinas com a Cl brasileira durante esse período. O ano de início em 1997 justificou-se pelo fato dele ser o primeiro ano em que um fascículo da área de $\mathrm{Cl}$ nacional foi indexado na SciELO. A escolha de encerramento no ano de 2016 justificou-se por completar um ciclo de 20 anos de análise.

Para identificação das citações à produção científica da $\mathrm{Cl}$ nacional inicialmente foi feita uma busca na base de dados SciELO por todos os documentos publicados entre 1997 e 2016 pelos periódicos nacionais de $\mathrm{Cl}$ analisados. Os periódicos nacionais que compuseram o corpus desta pesquisa foram: Ciência da Informação, Perspectivas em Ciência da Informação e Transinformação pelo fato de serem relevantes periódicos nacionais da área e serem os únicos periódicos nacionais da área indexados pela SciELO. Após esse levantamento, foi investigado se existiam e quais seriam as áreas do conhecimento que citavam os trabalhos do escopo da $\mathrm{Cl}$ publicados nesses periódicos. Entende-se que não é possível generalizar os resultados da área a partir da aferição de apenas três periódicos, mas perante a relevância dos periódicos de $\mathrm{Cl}$ selecionados para análise, considera-se, contudo, como um indicador bastante razoável para se dar respostas aos objetivos propostos. 
Para determinação da área citante ao conhecimento de $\mathrm{Cl}$ nacional foi considerada a área temática estabelecida pela SciELO para todos os periódicos dos documentos citantes e caso o periódico fosse classificado em mais de uma área temática de forma simultânea pela SciELO, todas essas áreas foram consideradas e computadas.

Por ser a classificação adotada pela SciELO muito específica, também foi realizado um trabalho de conversão dessas áreas temáticas para as áreas de conhecimento estabelecidas pelo Conselho Nacional de Desenvolvimento Científico e Tecnológico (CNPq), conforme tabela apresentada por Fernandes (2019).

\subsection{Segunda Etapa}

Avaliou-se o nível de interação estabelecido nos documentos das citações de outras disciplinas com a Cl nacional, através da análise de uma amostra não probabilística, com seleção por conveniência, de 15\% das 1092 citações de áreas externas concedidas à literatura produzida pelo campo na esfera nacional, identificados na primeira etapa, ou seja, 164 citações. O tamanho da amostra foi escolhido por julgar essa porcentagem um tamanho exequível de ser investigado, diante do tempo e recursos disponíveis para essa pesquisa.

Justificou-se a seleção de uma amostra não probabilística, uma vez que, as citações à produção científica da $\mathrm{Cl}$ nacional levantadas via SciELO na primeira etapa poderiam apresentar várias citações em duplicidade, fato que poderia gerar via sorteio aleatório simples para uma amostragem probabilística também uma amostra em duplicidade, e essa ocorrência prejudicaria o rigor que deve ser adotado numa pesquisa desse tipo, invalidando assim seus resultados.

A seleção das citações que constituíram a amostra ocorreu de acordo com a seguinte rotina: a lista de todos os documentos publicados entre 1997 e 2016 pelos respectivos periódicos nacionais de $\mathrm{Cl}$ identificada na primeira etapa foi ordenada por número de citações recebidas através de opção fornecida pela SciELO. O próximo passo foi fazer uma busca na SciELO de quantos documentos cada autor nacional reconhecidamente de $\mathrm{Cl}$ dos respectivos 
trabalhos mais citados havia publicado no período de 1997 a 2016 nos periódicos nacionais da área analisados. A seguir levantou-se quantas citações esse autor tinha recebido ao todo nesses documentos e posteriormente foram analisadas quantas e quais dessas eram citações oriundas de documentos publicados por periódicos de outras disciplinas. Essa rotina foi feita até completar a quantidade de amostras desejadas, ou seja, 164 citações de outras áreas ao conhecimento produzido pela área de $\mathrm{Cl}$ nacional. Na seleção dessa amostra (164 citações de outras áreas ao conhecimento produzido pela área de $\mathrm{Cl}$ nacional) não foram contabilizadas/consideradas as citações de outras áreas concedidas ao autor nacional de $\mathrm{Cl}$ que mais citações de outra(s) área(s) havia recebido. Essa exclusão teve o objetivo de eliminar algum viés como concentrar um elevado número de citações da amostra a um tópico específico de estudo da $\mathrm{Cl}$ e também distribuir a amostra por uma quantidade maior de autores.

Ainda durante a seleção das citações da amostra pode ter ocorrido a inclusão de um mesmo trabalho em seu somatório final, assim como pode ter ocorrido no somatório final da população, visto que, um mesmo trabalho de determinado periódico pode ter citado ao mesmo tempo trabalhos distintos dos periódicos nacionais de $\mathrm{Cl}$ analisados, fato que provocaria essa duplicidade e a ferramenta utilizada nesse levantamento, a SciELO, não oferece ferramentas para identificar e filtrar a ocorrência relatada anteriormente.

Como o objetivo desta etapa foi avaliar o nível de interação disciplinar com a $\mathrm{Cl}$, estabelecido pelos documentos das citações de outras áreas ao conhecimento produzido pela $\mathrm{Cl}$ nacional, adotou-se uma série de pressupostos propostos com base na literatura e nos significados dos três tipos de interação: multi, inter e transdisciplinar, discutidos anteriormente.

$\mathrm{O}$ primeiro deles considerou que as citações à literatura de $\mathrm{Cl}$ pertencentes à mesma área de interesse, ou seja, à própria $\mathrm{Cl}$, foram construídas sem nenhuma relação disciplinar, uma vez que nesta condição apenas pesquisador(es) da própria disciplina utilizou(zaram)-se do arcabouço teórico, metodológico e aplicado produzido pelo campo com o objetivo de avançar no conhecimento da área, não ocorrendo em nenhum desses casos uma relação mínima que seja entre disciplinas distintas de modo a ensejar algum 
outro tipo de relação disciplinar, seja ela multi, inter ou transdisciplinar. Essa cota de citações concedidas à $\mathrm{Cl}$ pela própria área não foi objeto de análise por não estar contemplada nos objetivos da pesquisa.

$\mathrm{O}$ segundo pressuposto foi de que todas as citações à literatura de $\mathrm{Cl}$ pertencentes às demais áreas do conhecimento poderiam ter estabelecido algum tipo de relação com a área.

O terceiro pressuposto diz respeito à pesquisa transdisciplinar que, a partir dos parâmetros teórico-conceituais apresentados no referencial teórico, ainda seria uma forma utópica de relação disciplinar, ainda distante de ser atingida nos moldes das atuais estruturas das comunidades científicas, dos regimes pedagógicos e da organização da instituição escolar. Por isso foi considerada como praticamente impossível de ser efetivada no conjunto de citações analisadas e caso ocorresse, sua representatividade não seria significativa.

Por fim, a pesquisa adotou o pressuposto de que, para que possa haver uma relação interdisciplinar com a $\mathrm{Cl}$, as citações concedidas à área devam ter sido originárias de trabalhos produzidos de forma coletiva entre pesquisador(es) de outra(s) disciplina(s) com pesquisador(es) da $\mathrm{Cl}$ (seja ele de formação ou atuação), ou sejam citações oriundas de trabalhos individuais desenvolvidos por investigador formado em $\mathrm{Cl}$, mas com atuação em outra área, ou citações oriundas de trabalhos individuais desenvolvidos por pesquisador formado em outra área, mas com atuação em $\mathrm{Cl}$.

Numa análise preliminar nos trabalhos das 164 citações da amostra, foram levantados dados relativos aos seguintes fatores considerados como contributivos para efetivação de relações disciplinares: número de autores, formação dos autores e área de atuação dos autores. Os dados foram identificados no campo autoria dos trabalhos e, também, em buscas na internet em sites como: Plataforma Lattes, Research Gate, Linkedin, sites das instituições de ensino dos autores, sites pessoais dos pesquisadores e buscadores da internet.

As classificações das formações e áreas de atuações dos autores das citações oriundas de trabalhos publicados em periódicos de outras áreas ao 
conhecimento da $\mathrm{Cl}$ brasileira foram divididas em cinco possibilidades: 1) $\mathrm{Cl} 1$;2) outra área exceto a $\mathrm{Cl}$; 3) outra área mais a $\mathrm{Cl}$; 4) outras áreas mais a $\mathrm{Cl}$; 5) outras áreas exceto a $\mathrm{Cl}$.

Os fatores número de autores, formação dos autores, área de atuação dos autores foram combinados para, a partir dos pressupostos estabelecidos na metodologia, determinar de modo quantitativo o nível de interação/relação verificado.

Após análise cruzada desses fatores, ver Quadro 1, foram considerados trabalhos disciplinares, sem interação, todos os documentos produzidos somente por autor(es) da área de $\mathrm{Cl}$ (de formação e atuação concomitantes), multidisciplinares, todos os documentos produzidos por uma única autoria de outra(s) área(s) do conhecimento (de formação e atuação concomitantes), todos os documentos produzidos por dois ou mais autores de outra mesma área do conhecimento (de formação e atuação concomitantes) e todos os documentos produzidos por dois ou mais autores pertencentes a outras áreas do conhecimento (de formação e atuação concomitantes). E com propriedades indicativas de relações interdisciplinares ${ }^{2}$ as pesquisas da amostra que se enquadraram no grupo de trabalhos produzidos por:

- um autor categorizado com formação em outra(s) área(s) do conhecimento mais $\mathrm{Cl}$ e com área de atuação somente em outra(s) áreas(s) do conhecimento ou em outra(s) área(s) do conhecimento mais $\mathrm{Cl}$ ou somente $\mathrm{Cl}$;

- um autor categorizado com formação em outra(s) área(s) do conhecimento que não a $\mathrm{Cl}$ e área de atuação em outras áreas e $\mathrm{Cl}$ ou somente $\mathrm{Cl}$ );

- um autor categorizado com formação em $\mathrm{Cl}$ e área de atuação em

\footnotetext{
${ }^{1}$ De acordo com o nível da tabela de área do conhecimento adotado nessa pesquisa para classificação das áreas de conhecimento, todos os autores formados em alguma das sub-áreas da ciência da informação a saber: teoria da informação, biblioteconomia e arquivologia, foram classificados como formados em ciência da informação.

2 Essas propriedades indicativas sinalizam que o texto analisado possuía via analise quantitativa algum aspecto significativo do fenômeno estudado, a interdisciplinaridade, e por isso deveria passar por uma análise mais aprofundada para verificar se a presença desse aspecto realmente refletiu na prática em uma pesquisa interdisciplinar.
} 
outra(s) área(s) ou outra(s) área(s) e Cl;

- dois ou mais autores categorizados com formação em outra(s) área(s) do conhecimento e pelo menos um deles mais $\mathrm{Cl}$ e com área de atuação em outra(s) área(s) ou outra(s) área(s) e $\mathrm{Cl}$ ou somente $\mathrm{Cl}$;

- dois ou mais autores categorizados com formação em outra(s) área(s) do conhecimento e com área de atuação em outra(s) área(s) do conhecimento e pelo menos um deles mais $\mathrm{Cl}$ ou com área de atuação somente em Cl;

- dois ou mais autores categorizados com formação em $\mathrm{Cl}$ e área de atuação em outra(s) área(s) ou outra(s) área(s) e Cl.

\section{Quadro 1 - Tipo de relação verificada na análise quantitativa da amostra das citações de outras áreas ao conhecimento de $\mathrm{Cl}$ nacional a partir dos pressupostos estabelecidos}

\begin{tabular}{|c|c|c|c|}
\hline \multirow{2}{*}{$\begin{array}{l}\text { Tipo de relação } \\
\text { verificada }\end{array}$} & \multicolumn{3}{|c|}{ Fatores combinados } \\
\hline & $\begin{array}{l}\text { Número de } \\
\text { Autores }\end{array}$ & $\begin{array}{l}\text { Formação dos } \\
\text { autores }\end{array}$ & $\begin{array}{l}\text { Atuação dos } \\
\text { autores }\end{array}$ \\
\hline Disciplinares & 1 ou mais & (e) $\mathrm{Cl}^{*}$ & (e) $\mathrm{Cl}^{*}$ \\
\hline \multirow{3}{*}{ Multidisciplinares } & 1 & (e) Outra(s) área(s) ${ }^{\star \star}$ & (e) Outra(s) área $(\mathrm{s})^{\star *}$ \\
\hline & 2 ou mais & $\begin{array}{l}\text { (e) Outra mesma } \\
\text { área }\end{array}$ & $\begin{array}{l}\text { (e) Outra mesma } \\
\text { área*** }\end{array}$ \\
\hline & 2 ou mais & (e) Outras áreas ${ }^{* * * *}$ & (e) Outras áreas ${ }^{\star * \star *}$ \\
\hline \multirow[t]{6}{*}{$\begin{array}{l}\text { Propriedades indicativas } \\
\text { de relações } \\
\text { interdisciplinares }\end{array}$} & 1 & $\begin{array}{l}\text { (e) Outra(s) área(s) e } \\
\mathrm{Cl}^{* \star \star \star *}\end{array}$ & $\begin{array}{l}\text { (e) Somente em } \\
\text { outra(s) área(s) ou } \\
\text { outra(s) área(s) e } \mathrm{Cl} \text { ou } \\
\text { somente } \mathrm{Cl}^{* * * * *}\end{array}$ \\
\hline & 1 & $\begin{array}{l}\text { (e) Outra(s) } \\
\text { área(s) })^{\star \star \star \star \star \star *}\end{array}$ & $\begin{array}{l}\text { (e) Outra(s) área(s) e } \\
\mathrm{Cl} \text { ou somente } \mathrm{Cl}^{\star \star \star \star \star \star}\end{array}$ \\
\hline & 1 & (e) $\mathrm{Cl}^{\star \star \star \star \star \star \star \star}$ & $\begin{array}{l}\text { (e) Outra(s) área(s) ou } \\
\text { outra(s) área(s) e } \\
\mathrm{Cl}^{* \star * \star \star \star *}\end{array}$ \\
\hline & 2 ou mais & $\begin{array}{l}\text { (e) Outra(s) área(s) e } \\
\mathrm{Cl}^{* \star * \star * * * \star}\end{array}$ & $\begin{array}{l}\text { (e) Somente em } \\
\text { outra(s) área(s) ou } \\
\text { outra(s) área(s) e } \mathrm{Cl} \text { ou } \\
\text { somente } \mathrm{Cl}^{\star \star \star \star \star \star \star \star \star}\end{array}$ \\
\hline & 2 ou mais & (e) Outra(s) área(s) & $\begin{array}{l}\text { (e) Outra(s) área(s) e } \\
\mathrm{Cl} \text { ou somente } \mathrm{Cl} \\
* * \star \star \star \star \star \star *\end{array}$ \\
\hline & 2 ou mais & (e) $\mathrm{Cl}^{* \star * \star * \star * \star * \star *}$ & $\begin{array}{l}\text { (e) Outra(s) área(s) ou } \\
\text { outras áreas e Cl } \\
* * \star * * * * * * *\end{array}$ \\
\hline
\end{tabular}

Fonte: Elaborado pelos autores.

- * 1 ou mais autores categorizados com formação e área de atuação concomitantes somente em Cl;

- ** 1 autor categorizado com formação e área de atuação em outra(s) área(s) do conhecimento que não a Cl. Por exemplo: 1 autor com formação e atuação em 
administração ou com formação em administração e ciência da computação e atuação em ciência da computação;

- ${ }^{* * *} 2$ ou mais autores categorizados com formação e área de atuação em outra área do conhecimento que não a Cl. Por exemplo: 2 autores com formação e atuação em ciência da computação;

- ${ }^{* \star * \star} 2$ ou mais autores categorizados com formação e área de atuação em outras áreas do conhecimento que não a $\mathrm{Cl}$. Por exemplo: 1 autor com formação e atuação em ciência da computação e outro autor com formação e atuação em administração;

- $\quad{ }^{* * \star * \star} 1$ autor categorizado com formação em outra(s) área(s) do conhecimento mais $\mathrm{Cl}$ e com área de atuação somente em outra(s) áreas(s) do conhecimento ou em outra(s) área(s) do conhecimento mais $\mathrm{Cl}$ ou somente $\mathrm{Cl}$. Por exemplo: 1 autor com formação em $\mathrm{Cl}$ e administração e área de atuação em administração ou área de atuação em administração e $\mathrm{Cl}$ ou área de atuação somente em $\mathrm{Cl}$;

- $\quad{ }^{* * * * * *} 1$ autor categorizado com formação em outra(s) área(s) do conhecimento que não a $\mathrm{Cl}$ e área de atuação em outras áreas e $\mathrm{Cl}$ ou somente $\mathrm{Cl}$. Por exemplo: 1 autor com formação em administração e ciência da computação, mas com área de atuação em computação e $\mathrm{Cl}$ ou com área de atuação somente em $\mathrm{Cl}$;

- ${ }^{* \star \star \star \star * *} 1$ autor categorizado com formação em $\mathrm{Cl}$ e área de atuação em outra(s) área(s) ou outra(s) área(s) e Cl. Por exemplo: 1 autor com formação em Cl, mas com área de atuação em administração ou área de atuação em administração e $\mathrm{Cl}$;

- $\quad * * * * * * * 2$ ou mais autores categorizados com formação em outra(s) área(s) do conhecimento e pelo menos um deles mais $\mathrm{Cl}$ e com área de atuação em outra(s) área(s) ou outra(s) área(s) e Cl ou somente Cl. Por exemplo: 2 autores com formação em administração e mais um autor também com formação em $\mathrm{Cl}$ e os 3 autores com área de atuação em administração ou 2 autores com área de atuação em administração mais 1 autor com área de atuação em $\mathrm{Cl}$ ou os 3 autores com área de atuação em $\mathrm{Cl}$;

- ${ }^{* * * * * * * * \star} 2$ ou mais autores categorizados com formação em outra(s) área(s) do conhecimento e com área de atuação em outra(s) área(s) do conhecimento e pelo menos um deles mais $\mathrm{Cl}$ ou com área de atuação somente em $\mathrm{Cl}$. Por exemplo: 3 autores, $1 \mathrm{com}$ formação em ciência da computação e dois com formação em administração e 2 autores com área de atuação em administração e outro com área de atuação em $\mathrm{Cl}$ ou os 3 com área de atuação somente em $\mathrm{Cl}$;

- ${ }^{* * * * * * * * * *} 2$ ou mais autores categorizados com formação em $\mathrm{Cl}$ e área de atuação em outra(s) área(s) ou outra(s) área(s) e Cl. Por exemplo: 2 autores com formação em $\mathrm{Cl}$ e os 2 autores com área de atuação em administração ou 1 autor com área de atuação em administração e $\mathrm{Cl}$ e o outro em administração ou 1 autor com área de atuação em $\mathrm{Cl}$ e o outro com área de atuação em administração.

Para determinar o real tipo de relação estabelecida entre a área de $\mathrm{Cl}$ e 0 conjunto de citações da amostra oriundas de trabalhos que se enquadraram no grupo de citações classificadas, a partir da análise quantitativa, com propriedades indicativas de relações interdisciplinares foi realizada uma análise qualitativa através da leitura integral do texto.

$\mathrm{Na}$ análise qualitativa, foram avaliados teorias/referências utilizadas e resultados obtidos, que são outros fatores considerados por Bicalho (2009) como 
contributivos para ocorrência de relações interdisciplinares. Para se determinar o tipo de relacionamento/interação verificado na análise qualitativa apoiou-se no guia adaptado de Bicalho (2009), conforme Quadro 2.

\section{Quadro 2 - Guia adaptado de Bicalho (2009) com as propriedades avaliadas na análise qualitativa indicativas de relações interdisciplinares}

\begin{tabular}{|c|c|}
\hline Propriedades & Ponderação \\
\hline \multicolumn{2}{|l|}{ 1. Formação acadêmica dos autores } \\
\hline Autoria única com formação única: outra área & 0 \\
\hline Autoria única com formação única: $\mathrm{Cl}$ & 0 \\
\hline Autoria única com formação múltipla: outras áreas exceto $\mathrm{Cl}$ & 0 \\
\hline Autoria única com formação múltipla: outra(s) área(s) e Cl & 3 \\
\hline Autoria múltipla com formação única: outra área & 0 \\
\hline Autoria múltipla com formação única: $\mathrm{Cl}$ & 0 \\
\hline Autoria múltipla com formação múltipla: outras áreas & 0 \\
\hline Autoria múltipla com formação múltipla: outra(s) área(s) e Cl & 3 \\
\hline \multicolumn{2}{|l|}{ 2. Área de atuação dos autores } \\
\hline Atuação estrita em Cl & 0 \\
\hline Atuação estrita em outra área & 0 \\
\hline Atuação estrita em outras áreas & 0 \\
\hline Atuações em mais de uma área: outra(s) área(s) e Cl & 3 \\
\hline \multicolumn{2}{|l|}{ 3. Embasamento conceitual/metodologia } \\
\hline Exclusivamente de outra(s) área(s) & 0 \\
\hline Exclusivamente da $\mathrm{Cl}$ & 0 \\
\hline Com predominância de teorias/técnicas da Cl & 1 \\
\hline Com predominância de teorias/técnicas outra(s) área(s) & 1 \\
\hline $\begin{array}{l}\text { Compartilhamento de teorias/técnicas das áreas }(\mathrm{Cl} \text { e outra(s) } \\
\text { área(s) }\end{array}$ & 3 \\
\hline \multicolumn{2}{|l|}{ 4. Resultados apresentados } \\
\hline Dirigidos somente a outra(s) área(s) & 0 \\
\hline Dirigidos somente a $\mathrm{Cl}$ & 0 \\
\hline Dirigidos predominantemente a outra(s) área(s) & 1 \\
\hline Dirigidos predominantemente à Cl & 1 \\
\hline Dirigidos à Cl e a outra(s) área(s) & 3 \\
\hline
\end{tabular}

Fonte: Adaptado de Bicalho (2009).

No guia apresentado no Quadro 2, foram listados todos os fatores que foram avaliados, nos trabalhos das citações de outras áreas ao conhecimento 
científico produzido pela $\mathrm{Cl}$ com propriedades indicativas de relações interdisciplinares, bem como uma nota/peso a ser atribuída para cada fator de acordo com a realidade observada na análise. Para o estabelecimento dessas notas, foram consideradas a partir da literatura estudada as possibilidades de um trabalho ter sido construído a partir de uma relação interdisciplinar, sendo zero para trabalhos sem nenhuma chance, um para trabalhos com alguma chance e três para trabalhos com maiores chances.

Ciente de que provavelmente nenhum trabalho reuniria, separadamente, todos os fatores elencados no guia, conforme muito bem observado por Bicalho (2009), somente foram consideradas citações oriundas de trabalhos construídas à base de uma relação interdisciplinar entre as outras disciplinas e a $\mathrm{Cl}$, aquelas que obtiveram, no mínimo, uma nota três na soma da análise das duas primeiras variáveis que foram: formação acadêmica dos autores e área de atuação dos autores e uma nota quatro na soma da análise das duas últimas variáveis analisadas, que foram: embasamento conceitual/metodologia e resultados apresentados.

Nos casos em que a nota na análise das duas primeiras variáveis fosse zero, mas com indicação de autoria com formação em $\mathrm{Cl}$ e atuação em outra(s) área(s) de maneira concomitante, ou formação em outra(s) área(s) e atuação em $\mathrm{Cl}$ de maneira concomitante e ainda uma dessas outras áreas fosse uma das beneficiadas com os resultados além da $\mathrm{Cl}$, o trabalho foi considerado interdisciplinar, se obtivesse uma nota quatro na soma da análise das duas últimas variáveis analisadas.

Ressalta-se que, a utilização do guia adaptado de Bicalho (2009) nesta análise, visou avaliar se o nível de integração entre teorias e metodologias das disciplinas em conexão possibilitava um enriquecimento mútuo, configurando assim a ocorrência de uma pesquisa interdisciplinar.

\section{APRESENTAÇÃO E ANÁLISE DOS RESULTADOS}

\subsection{Primeira Etapa}

$\mathrm{Na}$ análise das citações recebidas durante todo o período investigado 
(1997 a 2016) pelos trabalhos da área publicados entre 1997 a 2016 nos periódicos nacionais investigados, ver TAB. 1, verificou-se a ocorrência de 2817 citações na SciELO. Destas, 1725 (61,2\%) foram concedidas pela própria área. As demais citações foram concedidas por trabalhos das seguintes áreas: administração (5,9\%), saúde coletiva $(5,6 \%)$, educação $(4,1 \%)$, medicina $(2,4 \%)$, psicologia $(2,2 \%)$, enfermagem $(2,1 \%)$, sociologia $(2,0 \%)$, ciências da saúde $(1,5 \%)$, ciência da computação $(1,4 \%)$ e demais áreas $(11,5 \%)$. Nos casos em que não foi possível determinar uma área específica, foi utilizada a classificação pela grande área como: ciências sociais, ciências da saúde, engenharias e ciências humanas.

Constatou-se também que poucas áreas têm uma grande relação com a $\mathrm{Cl}$ nacional e muitas áreas têm uma pequena relação com a $\mathrm{Cl}$ nacional, uma vez que, apenas as cinco outras áreas que mais citaram a $\mathrm{Cl}$ nacional foram responsáveis por 20,2\% das citações concedidas à área enquanto as demais 49 outras áreas foram responsáveis por $18,5 \%$ das citações concedidas à $\mathrm{Cl}$ nacional.

Outra descoberta que chamou atenção foi o grande número de outras áreas que citaram o conhecimento produzido pelo campo no cenário nacional. De acordo com a tabela de áreas do conhecimento adotada para classificação das áreas, existem 103 outras áreas do conhecimento. Dessas aproximadamente metade (50) utilizou o conhecimento produzido pela $\mathrm{Cl}$ nacional nos 20 anos analisados. Nesta análise já foram descontadas as citações classificadas pelas grandes áreas.

Tabela 1 - Área de conhecimento dos trabalhos das citações concedidas à literatura de CI nacional no período de 1997 a 2016

\begin{tabular}{lrr}
\hline \multicolumn{1}{c}{ Área de conhecimento da citação } & $\begin{array}{c}\text { Número de } \\
\text { citações } \\
\text { concedidas }\end{array}$ & $\%$ \\
\hline Ciência da informação & 1725 & $61,2 \%$ \\
Administração & 165 & $5,9 \%$ \\
Saúde coletiva & 159 & $5,6 \%$ \\
Educação & 116 & $4,1 \%$ \\
Medicina & 68 & $2,4 \%$ \\
\hline
\end{tabular}




\begin{tabular}{lrr}
\hline Psicologia & 62 & $2,2 \%$ \\
Enfermagem & 60 & $2,1 \%$ \\
Sociologia & 56 & $2,0 \%$ \\
Ciências da saúde & 42 & $1,5 \%$ \\
Ciência da computação & 40 & $1,4 \%$ \\
Outras áreas & 324 & $11,6 \%$ \\
Total & $\mathbf{2 8 1 7}$ & $\mathbf{1 0 0 , 0 \%}$ \\
\hline
\end{tabular}

Fonte: Dados da pesquisa.

A seguir serão apresentadas as análises das citações por quinquênios. Os trabalhos de $\mathrm{Cl}$ publicados entre 1997 e 2001 nos periódicos nacionais investigados receberam um total de 109 citações na SciELO no período de 1997 a 2001 (primeiro quinquênio), conforme TAB. 2. Destas, 93 (85,3\%) foram concedidas por trabalhos da própria área do conhecimento. As demais citações foram concedidas por trabalhos das seguintes áreas: história e medicina (3,7\% cada), saúde coletiva $(2,8 \%)$, psicologia $(1,8 \%)$, educação, engenharia química e sociologia $(0,9 \%$ cada $)$.

Tabela 2 - Área de conhecimento dos trabalhos das citações concedidas à literatura de $\mathrm{Cl}$ nacional no período de 1997 a 2001

\begin{tabular}{lrr}
\hline Área de conhecimento da citação & $\begin{array}{c}\text { Número de citaçães } \\
\text { concedidas }\end{array}$ & \multicolumn{1}{c}{$\%$} \\
\hline Ciência da informação & 93 & $85,3 \%$ \\
História & 4 & $3,7 \%$ \\
Medicina & 4 & $3,7 \%$ \\
Saúde coletiva & 3 & $2,8 \%$ \\
Psicologia & 2 & $1,8 \%$ \\
Educação & 1 & $0,9 \%$ \\
Engenharia química & 1 & $0,9 \%$ \\
Sociologia & 1 & $0,9 \%$ \\
Total & $\mathbf{1 0 9}$ & $\mathbf{1 0 0 , 0 \%}$ \\
\hline
\end{tabular}

Fonte: Dados da pesquisa.

Os trabalhos de Cl publicados entre 1997 e 2006 nos periódicos nacionais investigados receberam um total de 512 citações na SciELO no período de 2002 a 2006 (segundo quinquênio), conforme TAB. 3. Ressalta-se que em trabalhos de três citações não foi possível estabelecer uma área e por esse motivo eles 
foram classificados pela grande área. Das 512 citações, 401 (78,3\%) foram concedidas por trabalhos da própria área do conhecimento. As demais citações foram concedidas por trabalhos das seguintes áreas: saúde coletiva $(4,7 \%)$, medicina $(3,3 \%)$, economia e educação $(2,7 \%$ cada), psicologia $(2,1 \%)$, administração (1,6\%), sociologia $(1,0 \%)$, enfermagem $(0,8 \%)$, nutrição $(0,6 \%)$ e demais áreas $(2,1 \%)$.

Tabela 3 - Área de conhecimento dos trabalhos das citações concedidas à literatura de CI nacional no período de 2002 a 2006

\begin{tabular}{lrr}
\hline Área de conhecimento da citação & $\begin{array}{c}\text { Número de citações } \\
\text { concedidas }\end{array}$ & $\%$ \\
\hline Ciência da informação & 401 & $78,3 \%$ \\
Saúde coletiva & 24 & $4,7 \%$ \\
Medicina & 17 & $3,3 \%$ \\
Economia & 14 & $2,7 \%$ \\
Educação & 14 & $2,7 \%$ \\
Psicologia & 11 & $2,1 \%$ \\
Administração & 8 & $1,6 \%$ \\
Sociologia & 5 & $1,0 \%$ \\
Enfermagem & 4 & $0,8 \%$ \\
Nutrição & 3 & $0,6 \%$ \\
Demais áreas & 11 & $2,1 \%$ \\
Total & $\mathbf{5 1 2}$ & $\mathbf{1 0 0 , 0 \%}$ \\
\hline
\end{tabular}

Fonte: Dados da pesquisa.

Os trabalhos de Cl publicados entre 1997 e 2011 nos periódicos nacionais investigados receberam um total de 1085 citações na SciELO no período de 2007 a 2011 (terceiro quinquênio), conforme TAB. 4. Ressalta-se que em trabalhos de 11 citações não foi possível estabelecer uma área e por esse motivo eles foram classificados pela grande área. Das 1085 citações, 679 (62,6\%) foram concedidas por trabalhos da própria área do conhecimento. As demais citações foram concedidas por trabalhos das seguintes áreas: saúde coletiva $(7,1 \%)$, administração $(5,0 \%)$, educação $(3,8 \%)$, enfermagem $(2,6 \%)$, sociologia $(2,5 \%)$, medicina (2,4\%), psicologia (1,9\%), ciência da computação (1,8\%), comunicação $(1,1 \%)$ e demais áreas $(9,2 \%)$. 
Tabela 4 - Área de conhecimento dos trabalhos das citações concedidas à literatura de $\mathrm{Cl}$ nacional no período de 2007 a 2011

\begin{tabular}{lrr}
\hline \multicolumn{1}{c}{ Área de conhecimento da citação } & $\begin{array}{c}\text { Número de citações } \\
\text { concedidas }\end{array}$ & $\%$ \\
\hline Ciência da informação & 679 & $62,6 \%$ \\
Saúde coletiva & 77 & $7,1 \%$ \\
Administração & 54 & $5,0 \%$ \\
Educação & 41 & $3,8 \%$ \\
Enfermagem & 28 & $2,6 \%$ \\
Sociologia & 27 & $2,5 \%$ \\
Medicina & 26 & $2,4 \%$ \\
Psicologia & 21 & $1,9 \%$ \\
Ciência da computação & 20 & $1,8 \%$ \\
Comunicação & 12 & $1,1 \%$ \\
Demais áreas & 100 & $9,2 \%$ \\
Total & $\mathbf{1 0 8 5}$ & $\mathbf{1 0 0 , 0 \%}$ \\
\hline
\end{tabular}

Fonte: Dados da pesquisa.

Os trabalhos de CI publicados entre 1997 e 2016 nos periódicos nacionais investigados receberam um total de 1111 citações na SciELO no período de 2012 a 2016 (quarto quinquênio), conforme TAB. 5. Ressalta-se que para trabalhos de 60 citações não foi possível estabelecer uma área e por esse motivo eles foram classificados pela grande área. Das 1111 citações, 552 (49,7\%) foram concedidas por trabalhos da própria área do conhecimento. As demais citações foram concedidas por trabalhos das seguintes áreas do conhecimento: administração $(9,3 \%)$, educação $(5,4 \%)$, saúde coletiva $(5,0 \%)$, ciências da saúde $(3,1 \%)$, engenharia de produção $(2,6 \%)$, enfermagem e psicologia $(2,5 \%$ cada), sociologia $(2,1 \%)$, medicina $(1,9 \%)$ e demais áreas $(16,1 \%)$.

Tabela 5 - Área de conhecimento dos trabalhos das citações concedidas à literatura de $\mathrm{Cl}$ nacional no período de 2012 a 2016

\begin{tabular}{lrr}
\hline Área de conhecimento da citação & $\begin{array}{c}\text { Número de citações } \\
\text { concedidas }\end{array}$ & $\%$ \\
\hline Ciência da informação & 552 & $49,7 \%$ \\
Administração & 103 & $9,3 \%$ \\
Educação & 60 & $5,4 \%$ \\
Saúde coletiva & 55 & $5,0 \%$ \\
\hline
\end{tabular}




\begin{tabular}{lrr}
\hline Ciências da saúde & 34 & $3,1 \%$ \\
Engenharia de produção & 29 & $2,6 \%$ \\
Enfermagem & 28 & $2,5 \%$ \\
Psicologia & 28 & $2,5 \%$ \\
Sociologia & 23 & $2,1 \%$ \\
Medicina & 21 & $1,9 \%$ \\
Ciência da computação & 178 & $16,1 \%$ \\
Total & $\mathbf{1 1 1 1}$ & $\mathbf{1 0 0 , 0 \%}$ \\
\hline
\end{tabular}

Fonte: Dados da pesquisa.

$\mathrm{Na}$ análise da primeira etapa foi investigada apenas a porcentagem das citações de outras áreas na $\mathrm{Cl}$, mas também seria importante investigar o peso dessas citações em relação ao total de citações recebidas naquela área citante a produção científica da $\mathrm{Cl}$, uma vez que esse levantamento permitiria levantar o real percentual de contribuição da $\mathrm{Cl}$ para determinada área externa. Por exemplo, se os artigos de medicina citaram no total 10.000 trabalhos e destes 50 trabalhos fossem de periódicos da área, então poder-se-ia concluir que a $\mathrm{Cl}$ contribui com $0,5 \%$ nesta área. Devido à complexa trajetória selecionada para obtenção e análise dos dados não foi possível realizar essa análise nessa fase da pesquisa, mas os autores indicam essa análise como trabalhos futuros.

Em uma análise evolutiva do período pesquisado, 1997-2016, observouse que a cada quinquênio analisado a $\mathrm{Cl}$ brasileira parece ter tido maior notoriedade por outras áreas do conhecimento, refletida nas citações concedidas à área por essas outras áreas. Essa constatação pode indicar que a $\mathrm{Cl}$ nacional está num processo crescente de construção de um domínio teórico e metodológico disciplinar, caminhando para se tornar um campo maduro, com massa crítica evoluída e que o fato observado por Souza (2011) para quem o campo constrói seus laços interdisciplinares de forma unidimensional, a princípio, parece ter evoluído. Mas essa hipótese ainda carece de estudos mais aprofundados como apontado anteriormente, uma vez que seria importante averiguar também o peso das citações da área de $\mathrm{Cl}$ em relação ao total de citações recebidas por uma determinada área.

Esse "empréstimo" de conhecimento do campo a outras disciplinas, verificado via análise de citação, não permite identificar o nível de relação 
disciplinar (multi, inter ou transdisciplinar) estabelecida. Esta análise do nível de relação disciplinar foi realizada na segunda etapa desta pesquisa.

\subsection{SEgunda Etapa}

$\mathrm{Na}$ análise da primeira etapa foram levantadas ao todo 1725 citações de documentos da área para o conhecimento produzido pela própria área na esfera nacional e 1092 citações de documento de outras áreas para documentos produzidos pela área no cenário nacional.

Conforme pressuposto apresentado no item 3, Metodologia, as 1725 citações concedidas à área oriundas de documentos da própria área, foram consideradas disciplinares e as mesmas não foram objeto de estudo nesse trabalho por não estarem contempladas nos objetivos da pesquisa.

Já as 1092 citações de documentos de outras áreas para documentos produzidos pela área no cenário nacional foram consideradas como construídas, a princípio, com base em alguma relação disciplinar (multi, inter ou transdisciplinar) com a $\mathrm{Cl}$ nacional.

Para averiguar qual o tipo de relação disciplinar estabelecida, fez-se necessário uma análise minuciosa nas citações originárias de periódicos de outras áreas aos trabalhos de $\mathrm{Cl}$ publicados nos periódicos nacionais investigados. Devido à quantidade de citações concedidas, optou-se por fazer na segunda etapa uma análise em uma amostra não probabilística selecionada por conveniência de 15\% das 1092 citações, ou seja, uma amostra de 164 citações conforme explicado na metodologia.

No que tange o fator número de autores, ver GRAF. 1, o resultado da análise da amostra revelou que dentre as 164 citações analisadas, 25 (15,2\%) eram de trabalhos de uma única autoria. O restante das 139 citações da amostra analisada foram trabalhos construídos por dois ou mais autores. Com dois autores obteve-se 54 (32,9\%) citações, com três autores obteve-se 28 (17,1\%) citações, com quatro autores obteve-se $34(20,7 \%)$ citações e com cinco ou mais autores foram 23 (14\%) citações.

Destaca-se que a análise do número de autores visou avaliar de forma 
quantitativa a partir dos pressupostos assumidos na metodologia, combinando a análise cruzada dos fatores área de atuação versus formação dos autores, se estava ocorrendo no trabalho analisado uma interlocução entre pesquisadores de outras áreas com pesquisadores da $\mathrm{Cl}$. Essa análise ainda foi relevante para análise da variável "Formação acadêmica dos autores" estabelecida no guia adaptado de Bicalho (2009), instrumento utilizado por essa pesquisa para análise qualitativa.

\section{Gráfico 1 - Número de autores dos trabalhos da amostra das citações de outras áreas ao conhecimento produzido pela $\mathrm{Cl}$ nacional}

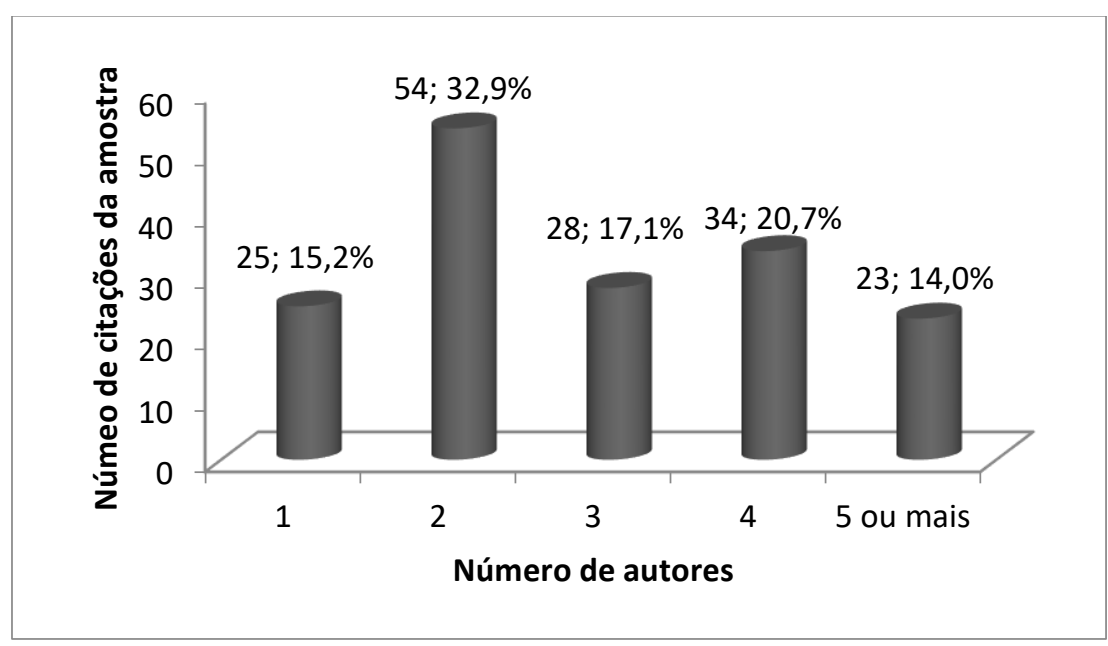

Fonte: Dados da pesquisa.

No que tange a análise cruzada dos fatores área de atuação versus formação dos autores referentes às 25 citações da amostra provenientes de trabalhos que foram classificados como autoria única, o resultado da análise quantitativa de acordo com os pressupostos dessa pesquisa revelou que 0 trabalho de uma citação foi considerado disciplinar, trabalhos de 20 citações foram considerados multidisciplinares e trabalhos de quatro citações apresentaram propriedades indicativas de terem sido construídos a base de uma relação interdisciplinar, e por isso, passaram por uma análise qualitativa por meio da leitura integral do texto e da utilização do guia adaptado de Bicalho (2009) com o objetivo de se determinar o real nível de relação/interação (multi, inter ou transdisciplinar) estabelecido nos trabalhos dessas citações..

O resultado dessa análise qualitativa revelou que dentre as quatro citações representadas por trabalhos classificados com autoria única avaliadas 
pela leitura integral do texto e a utilização do guia adaptado de Bicalho (2009), uma foi considerada disciplinar e três interdisciplinares.

A tabela 6 sintetiza o resultado final observado nas análises qualiquantitativas das 25 citações referentes aos trabalhos de autoria única que compuseram a amostra.

\section{Tabela 6 - Combinações utilizadas para determinação do tipo de relacionamento verificado nas citações da amostra oriundas de pesquisas com autoria única para o cenário nacional}

\begin{tabular}{|c|c|c|c|c|}
\hline $\begin{array}{l}\mathrm{N}^{\circ} \text { de } \\
\text { autores }\end{array}$ & $\begin{array}{l}\text { Combinação de formação x } \\
\text { atuação }\end{array}$ & $\begin{array}{l}\text { Casos } \\
\text { observa- } \\
\text { dos }\end{array}$ & $\begin{array}{c}\text { Tipo de } \\
\text { relacionamento } \\
\text { / interação } \\
\text { verificado } \\
\end{array}$ & $\begin{array}{c}\text { Modo de } \\
\text { determinação } \\
\text { do tipo de } \\
\text { relacionamento }\end{array}$ \\
\hline \multirow[t]{9}{*}{1 autor } & $\begin{array}{l}\text { Formação e atuação concomitante } \\
\text { somente em outra(s) área(s) }\end{array}$ & 20 & Multidisciplinar & $\begin{array}{l}\text { Pressupostos } \\
\text { (Quantitativo) }\end{array}$ \\
\hline & $\begin{array}{l}\text { Formação em outra(s) área(s) } \\
\text { mais atuação em outra(s) área(s) } \\
\text { mais Cl }\end{array}$ & 0 & Não se aplica & $\begin{array}{l}\text { Pressupostos } \\
\text { (Quantitativo) }\end{array}$ \\
\hline & $\begin{array}{l}\text { Formação em outra(s) área(s) } \\
\text { mais atuação somente em } \mathrm{Cl}\end{array}$ & 0 & Não se aplica & $\begin{array}{l}\text { Pressupostos } \\
\text { (Quantitativo) }\end{array}$ \\
\hline & $\begin{array}{l}\text { Formação concomitante em } \\
\text { outra(s) área(s) mais } \mathrm{Cl} \text { mais }\end{array}$ & 3 & Interdisciplinar & Leitura integral \\
\hline & $\begin{array}{l}\text { atuação em outra(s) área(s) mais } \\
\mathrm{Cl} \text { ou somente } \mathrm{Cl}\end{array}$ & 1 & Disciplinar & $\begin{array}{l}\text { do texto } \\
\text { (Qualitativo) }\end{array}$ \\
\hline & $\begin{array}{l}\text { Formação concomitante em } \\
\text { outra(s) área(s) mais Cl mais } \\
\text { atuação em outra(s) área(s) }\end{array}$ & 0 & Não se aplica & $\begin{array}{l}\text { Pressupostos } \\
\text { (Quantitativo) }\end{array}$ \\
\hline & $\begin{array}{l}\text { Formação e atuação concomitante } \\
\text { somente em } \mathrm{Cl}\end{array}$ & 1 & Disciplinar & $\begin{array}{l}\text { Pressupostos } \\
\text { (Quantitativo) }\end{array}$ \\
\hline & $\begin{array}{l}\text { Formação somente em } \mathrm{Cl} \text { mais } \\
\text { atuação em outra(s) área(s) }\end{array}$ & 0 & Não se aplica & $\begin{array}{l}\text { Pressupostos } \\
\text { (Quantitativo) }\end{array}$ \\
\hline & $\begin{array}{l}\text { Formação somente em } \mathrm{Cl} \text { mais } \\
\text { atuação em outra(s) área(s) mais } \\
\mathrm{Cl}\end{array}$ & 0 & Não se aplica & $\begin{array}{l}\text { Pressupostos } \\
\text { (Quantitativo) }\end{array}$ \\
\hline Total & & $\begin{array}{c}20 \\
3 \\
2\end{array}$ & $\begin{array}{l}\text { Multidisciplinar } \\
\text { Interdisciplinar } \\
\text { Disciplinar }\end{array}$ & $\begin{array}{l}\text { Pressupostos } \\
\text { e leitura } \\
\text { integral do } \\
\text { texto } \\
\text { (Quali/Quanti) }\end{array}$ \\
\hline
\end{tabular}

Fonte: Dados da pesquisa.

No que tange a análise cruzada dos fatores área de atuação versus formação dos autores referentes aos trabalhos das 139 citações da amostra que foram classificados como autoria múltipla, o resultado da análise quantitativa de acordo com os pressupostos dessa pesquisa revelou que trabalhos de duas citações foram considerados disciplinares, trabalhos de 121 citações foram 
considerados multidisciplinares e trabalhos 16 citações apresentaram propriedades indicativas de terem sido construídos a base de uma relação interdisciplinar, e por isso, passaram por uma análise qualitativa por meio da leitura integral do texto e a utilização do guia adaptado de Bicalho (2009) com o objetivo de se determinar o real nível de relação/interação (multi, inter ou transdisciplinar) estabelecido nos trabalhos dessas citações.

O resultado dessa análise qualitativa revelou que dentre as 16 citações representadas por trabalhos classificados com autoria múltipla avaliadas pela leitura integral do texto e da utilização do guia adaptado de Bicalho (2009), uma foi considerada disciplinar, dez foram consideradas multidisciplinares e cinco interdisciplinares.

A tabela 7 sintetiza o resultado final observado nas análises qualiquantitativas das 139 citações referentes aos trabalhos de autoria múltipla que compuseram a amostra.

\section{Tabela 7 - Combinações utilizadas para determinação do tipo de relacionamento verificado nas citações da amostra oriundas de pesquisas com autoria múltipla avaliadas para o cenário nacional}

\begin{tabular}{|c|c|c|c|c|}
\hline $\begin{array}{l}N^{\circ} \text { de } \\
\text { autores }\end{array}$ & $\begin{array}{l}\text { Combinação de formação x } \\
\text { atuação }\end{array}$ & $\begin{array}{l}\text { Casos } \\
\text { observa- } \\
\text { dos }\end{array}$ & $\begin{array}{c}\text { Tipo de } \\
\text { relacionamento } \\
\text { / interação } \\
\text { verificado }\end{array}$ & $\begin{array}{c}\text { Modo de } \\
\text { determinação } \\
\text { do tipo de } \\
\text { relacionamento }\end{array}$ \\
\hline $\begin{array}{l}2 \text { ou } \\
\text { mais }\end{array}$ & $\begin{array}{l}\text { Formação e atuação concomitante } \\
\text { somente em outra(s) área(s) }\end{array}$ & 121 & Multidisciplinar & $\begin{array}{l}\text { Pressupostos } \\
\text { (Quantitativo) }\end{array}$ \\
\hline \multirow[t]{9}{*}{ autores } & $\begin{array}{l}\text { Formação em outra(s) área(s) } \\
\text { mais atuação em outra(s) área(s) } \\
\text { mais Cl }\end{array}$ & 2 & Multidisciplinar & $\begin{array}{l}\text { Leitura integral } \\
\text { do texto } \\
\text { (Qualitativo) }\end{array}$ \\
\hline & $\begin{array}{l}\text { Formação em outra(s) área(s), } \\
\text { mas atuação somente em } \mathrm{Cl}\end{array}$ & 0 & Não se aplica & $\begin{array}{l}\text { Pressupostos } \\
\text { (Quantitativo) }\end{array}$ \\
\hline & Formação concomitante em & 5 & Interdisciplinar & \\
\hline & outras áreas mais $\mathrm{Cl}$ mais atuação & 7 & Multidisciplinar & Leitura integral \\
\hline & $\begin{array}{l}\text { em outra(s) área(s) mais } \mathrm{Cl} \text { ou } \\
\text { somente } \mathrm{Cl}\end{array}$ & 1 & Disciplinar & $\begin{array}{l}\text { do texto } \\
\text { (Qualitativo) }\end{array}$ \\
\hline & $\begin{array}{l}\text { Formação concomitante em } \\
\text { outras áreas mais } \mathrm{Cl} \text { mais atuação } \\
\text { em outra(s) área(s) }\end{array}$ & 1 & Multidisciplinar & $\begin{array}{l}\text { Leitura integral } \\
\text { do texto } \\
\text { (Qualitativo) }\end{array}$ \\
\hline & $\begin{array}{l}\text { Formação e atuação concomitante } \\
\text { somente em Cl }\end{array}$ & 2 & Disciplinar & $\begin{array}{l}\text { Pressupostos } \\
\text { (Quantitativo) }\end{array}$ \\
\hline & $\begin{array}{l}\text { Formação somente em } \mathrm{Cl} \text { mais } \\
\text { atuação em outra(s) área(s) }\end{array}$ & 0 & Não se aplica & $\begin{array}{l}\text { Pressupostos } \\
\text { (Quantitativo) }\end{array}$ \\
\hline & $\begin{array}{l}\text { Formação somente em } \mathrm{Cl} \text { mais } \\
\text { atuação em outra(s) área(s) mais } \\
\mathrm{Cl}\end{array}$ & 0 & Não se aplica & $\begin{array}{l}\text { Pressupostos } \\
\text { (Quantitativo) }\end{array}$ \\
\hline
\end{tabular}


Total

$\begin{aligned} 131 & \text { Multidisciplinar } \\ 5 & \text { Interdisciplinar } \\ 3 & \text { Disciplinar }\end{aligned}$
Pressupostos

e leitura

integral do

texto

(Quali/Quanti)

Fonte: Dados da pesquisa.

No total, o resultado da análise quantitativa realizada nas citações referentes aos 164 trabalhos da amostra revelaram que trabalhos de três citações foram considerados disciplinares, trabalhos de 141 citações foram considerados multidisciplinares e trabalhos de 20 citações apresentaram propriedades indicativas de terem sido construídos a base de uma relação interdisciplinar, e por isso, passaram por uma análise mais aprofundada por meio da leitura integral do texto e da utilização do guia adaptado de Bicalho (2009) com o objetivo de se determinar o real nível de relação/interação (multi, inter ou transdisciplinar) estabelecido nos trabalhos dessas citações.

O resultado total da análise qualitativa revelou que dentre as 20 citações representadas por trabalhos classificados com autoria única e múltipla avaliadas pela leitura integral do texto e da utilização do guia adaptado de Bicalho (2009), duas foram consideradas disciplinares, 10 foram consideradas multidisciplinares e oito interdisciplinares.

Com a finalidade de facilitar a visualização, a tabela 8 sintetiza o resultado final observado nas análises quali-quantitativas de todas as 164 citações referentes aos trabalhos de autoria única e múltipla que compuseram a amostra em âmbito nacional.

Tabela 8 - Tipo de relacionamento verificado a partir das análises qualiquantitativas realizadas nas 164 citações referentes a trabalhos de autoria única e múltipla que compuseram a amostra

\begin{tabular}{|c|c|c|c|}
\hline Número de autores & $\begin{array}{c}\text { Casos } \\
\text { observados }\end{array}$ & $\begin{array}{c}\text { Tipo de } \\
\text { relacionamento/ } \\
\text { interação } \\
\text { verificado }\end{array}$ & $\begin{array}{c}\text { Modo de } \\
\text { determinação } \\
\text { do tipo de } \\
\text { relacionamento }\end{array}$ \\
\hline $\begin{array}{c}\text { Subtotal referente às } 25 \\
\text { pesquisas da amostra de } \\
\text { autoria única }\end{array}$ & $\begin{array}{r}20 \\
3 \\
2\end{array}$ & $\begin{array}{l}\text { Multidisciplinar } \\
\text { Interdisciplinar } \\
\text { Disciplinar }\end{array}$ & $\begin{array}{l}\text { Pressupostos e } \\
\text { leitura integral } \\
\text { do texto } \\
\text { (Quali/Quanti) }\end{array}$ \\
\hline $\begin{array}{l}\text { Subtotal referente às } 139 \\
\text { pesquisas da amostra de } \\
\text { autoria múltipla }\end{array}$ & $\begin{array}{r}131 \\
5 \\
3\end{array}$ & $\begin{array}{l}\text { Multidisciplinar } \\
\text { Interdisciplinar } \\
\text { Disciplinar }\end{array}$ & $\begin{array}{l}\text { Pressupostos e } \\
\text { leitura integral }\end{array}$ \\
\hline
\end{tabular}




\begin{tabular}{crll} 
& & do texto \\
Total geral dos & 151 & Multidisciplinar & $\begin{array}{l}\text { (Quali/Quanti) } \\
\text { Pressupostos e }\end{array}$ \\
$\begin{array}{c}\text { resultados das análises } \\
\text { quali-quantitativas das }\end{array}$ & 8 & Interdisciplinar & $\begin{array}{l}\text { leitura integral } \\
\text { do texto } \\
\begin{array}{c}164 \text { pesquisas da } \\
\text { amostra }\end{array}\end{array}$ \\
\hline
\end{tabular}

Fonte: Dados da pesquisa.

Apesar dos dados da amostra não poderem ser generalizados para a população, uma vez que foi utilizado o método de amostragem não probabilística, seus resultados sugerem que um percentual razoável das citações referentes aos trabalhos de outras áreas aos artigos produzidos nos periódicos nacionais de $\mathrm{Cl}$ analisados foram desenvolvidas a base de alguma interação com a área. Observou-se que em trabalhos de 159 citações, o que equivale $96,95 \%$ dos trabalhos das 164 citações da amostra, apresentaram essa característica. Mas na avaliação do tipo de relacionamento efetuado verificou-se que a porcentagem dos trabalhos das citações que efetivamente podem ser considerados interdisciplinares com a $\mathrm{Cl}$ foi pequena, oito trabalhos, ou seja, 4,87\% dos trabalhos das 164 citações da amostra analisada, fato que não sustenta a característica interdisciplinar da $\mathrm{Cl}$ a partir dos trabalhos das citações de outras áreas que estabeleceram alguma relação com o campo no cenário nacional.

Ainda que a pesquisa tenha adotado como pressuposto que seria praticamente impossível de ser efetivado algum tipo de relação transdisciplinar, esse tipo de relação foi avaliada nos trabalhos das 20 citações que passaram pela análise qualitativa, as quais, devido às suas características, seriam as mais propensas a apresentarem, além de uma relação interdisciplinar, também uma relação transdisciplinar. Ao final da análise não foi encontrada uma relação transdisciplinar nos trabalhos das citações avaliadas.

Por fim, verificou-se que a porcentagem de trabalhos das 164 citações da amostra que realmente praticaram uma relação interdisciplinar com a $\mathrm{Cl}$ brasileira foi pequena indicando que os trabalhos interdisciplinares de outras áreas com a $\mathrm{Cl}$ nacional ainda são incipientes. 


\section{CONCLUSÕES}

Observou-se uma relação disciplinar distinta a cada quinquênio, medida a partir das citações concedidas por trabalhos das demais áreas do conhecimento à área.

Em todo o período avaliado, 1997-2016, verificou-se que, no cenário nacional, já excluídas as citações concedidas pela própria área, as disciplinas que mais se relacionaram com a $\mathrm{Cl}$ foram respectivamente: administração, saúde coletiva, educação, medicina, psicologia. Essas 5 outras disciplinas juntas foram responsáveis por $20,2 \%$ das citações concedidas à $\mathrm{Cl}$ brasileira enquanto as demais 49 outras áreas foram responsáveis por 18,5\% das citações concedidas à $\mathrm{Cl}$ nacional.

As citações ao conhecimento de $\mathrm{Cl}$ na literatura brasileira, refletiram justamente a relevância que atingiram as diferentes temáticas trabalhadas pela área nesses últimos 20 anos, destacando-se as temáticas de cunho sociais como: gestão da informação e todas as outras suas sub-temáticas, bem como, os trabalhos da área na saúde principalmente aqueles oriundos do Programa de Pós-Graduação Stricto Sensu em Informação e Comunicação em Saúde oferecido pelo Instituto de Comunicação e Informação Científica e Tecnológica em Saúde, da Fundação Oswaldo Cruz, e os publicados no GT na ANCIB denominado Informação \& Saúde.

Os dados revelaram que o conhecimento produzido pela $\mathrm{Cl}$ brasileira foi de maior importância para um número reduzido de disciplinas, embora subsidiasse a construção do conhecimento de um número representativo de áreas, ainda que sem muito impacto, visto que, 50 áreas externas à $\mathrm{Cl}$, das 103 áreas externas relacionadas pela tabela adotada, utilizaram, em algum momento, o conhecimento produzido pela $\mathrm{Cl}$ brasileira. Esse resultado pode indicar que essas extras disciplinas que mais se relacionaram com a $\mathrm{Cl}$ nacional seriam também as mais propensas de efetivarem uma relação interdisciplinar com a área no cenário nacional.

Nas últimas duas décadas, foi possível constatar um suposto avanço epistemológico atingido pela área no cenário nacional que já mantém um nível 
de relação disciplinar no qual a área assumiu também o papel de fornecedora de conhecimentos para as demais áreas e não sendo apenas a receptora como indicado por trabalhos passados (PAIM et al., 2001; BICALHO, 2009; SOUZA, 2011; SANTANA, 2012). Essa hipótese levantada anteriormente deverá ser objeto de estudo de pesquisas posteriores, visto que, esse suposto avanço epistemológico foi aferido pela dispersão de conhecimentos da área ou pela difusão de trabalhos da área em outras áreas, que não é um método ideal para tal finalidade.

Uma possível explicação para o elevado índice de citações concedidas por outras áreas ao conhecimento de $\mathrm{Cl}$ nacional, pode ser pelo fato de que vários pesquisadores de outras áreas formados também em $\mathrm{Cl}$ não conseguirem atuar na área devido ao número restrito de Programas de Pós-Graduação em Ciência da Informação existentes no Brasil (20 Programas acadêmicos e nove profissionais)3, ocasionando, assim, no retorno desses pesquisadores para suas áreas de origem. E esses por sua vez levariam para suas áreas o conhecimento adquirido na $\mathrm{Cl}$. Essa hipótese levantada deverá ser objeto de estudo de pesquisa posteriores.

A pesquisa verificou ainda a existência de uma justificativa/característica, potencializadora de realização de pesquisas interdisciplinares com a área, a saber: a questão de seu conhecimento também ser utilizado pelas demais áreas científicas.

$\mathrm{Na}$ etapa desta pesquisa que visou identificar o tipo de interação (multi, inter ou transdisciplinar) estabelecida entre as demais áreas e a $\mathrm{Cl}$, verificou-se que o índice de porcentagem dos trabalhos das citações da amostra que realmente foram construídos à base de uma relação interdisciplinar para 0 cenário nacional (4,87\%), não sustenta a característica interdisciplinar da $\mathrm{Cl}$, a partir dos trabalhos de outras áreas que estabelecem alguma relação com a $\mathrm{Cl}$. Estudos mais aprofundados se fazem necessários, uma vez que, devido a metodologia utilizada, amostragem não probabilística, essa constatação não pode ser conclusiva, ela apenas permite a geração de hipóteses, nesse caso

\footnotetext{
${ }^{3}$ De acordo com dados retirados no site da ANCIB. Disponível em:

https://www.ancib.org.br/menu-lateral/revistas-da-ancib. Acesso em: 2 de maio de 2019.
} 
específico a hipótese de que a área não seja interdisciplinar.

O nível de relação predominantemente verificado na amostra referente às pesquisas das citações de outras áreas à literatura de $\mathrm{Cl}$ em nível nacional foi justamente aquele sugerido por Paim et al. (2001, p. 20) ao criticar a questão da interdisciplinaridade na $\mathrm{Cl}$. As autoras afirmaram "que, da forma como é proposta e discutida, a interdisciplinaridade na área resume-se à prática multidisciplinar ou pluridisciplinar, na melhor das hipóteses."

A literatura científica sobre interdisciplinaridade apresenta uma série de resistências/obstáculos ao empreendimento de uma pesquisa interdisciplinar, a saber: o institucional, o epistemológico, o psicossociológico, o cultural, o metodológico, o de formação profissional e o material. (GUSDORF apud JAPIASSU, 1976; GUSDORF, 2006; FAZENDA, 2011; BRIGGS; MICHAUD, 1972).

A partir da constatação de que uma porcentagem e quantidade elevada de outras disciplinas utilizam o conhecimento produzido pela área, essa pesquisa aventou a possibilidade de que a área tenha evoluído na construção de seu domínio disciplinar, o qual já seria capaz de fornecer sustentação epistemológica para a evolução de diversas outras disciplinas. Então, infere-se que, ou essa provável evolução epistemológica do campo disciplinar da $\mathrm{Cl}$, alcançada nesses últimos anos, não tenha ocorrido e o campo ainda possua uma tímida disciplinaridade, como apontou, por exemplo, Bicalho (2009) e Souza (2011), ou realmente tenha ocorrido a provável evolução epistemológica, mas ela ainda não seja capaz de promover uma pesquisa interdisciplinar entre as demais áreas do conhecimento e a $\mathrm{Cl}$, ou que a questão para a não efetivação de pesquisas interdisciplinares entre as outras áreas e a $\mathrm{Cl}$, como verificado na amostra analisada, seja outra, como a superação das barreiras, registradas na literatura, que dificultam a realização de pesquisas interdisciplinares.

Os resultados também demonstraram que o simples levantamento de disciplinas que utilizam o conhecimento da $\mathrm{Cl}$ como metodologia para avaliar o nível de relação disciplinar seria uma metodologia frágil e bem semelhante à metodologia utilizada por vários pesquisadores que avaliam a interdisciplinaridade da área a partir somente do levantamento de outras áreas 
utilizadas pela $\mathrm{Cl}$, uma vez que esse método consegue no máximo apontar que houve uma correlação entre as áreas, mas não permite determinar o alcance da correlação. Se esse método tivesse sido utilizado para avaliar o tipo de interação estabelecida entre as demais áreas e a $\mathrm{Cl}$ nacional, teria modificado completamente os resultados dessa pesquisa, uma vez que, consideraria toda a porcentagem de citações de outras disciplinas à $\mathrm{Cl}(38,8 \%$ das citações avaliadas) como interdisciplinares.

Nessas perspectivas os resultados da pesquisa trouxe insumos concretos que validam as reflexões daquela corrente de pesquisadores que contestam as metodologias utilizadas nos estudos sobre interdisciplinaridade na área (GOMES, 2001; SANTOS NETO et al., 2017) e também para a corrente que defende que o campo não seja interdisciplinar (PAIM, et al., 2001; BICALHO, 2009; SANTANA, 2012; HIGINO; DUMONT, 2012).

\section{REFERÊNCIAS}

BICALHO, Lucinéia Maria; OLIVEIRA, Marlene. Aspectos conceituais da transdisciplinaridade e a pesquisa em Ciência da Informação. Informação \& Sociedade: estudos, João Pessoa, v. 21, n. 2, p. 87-102, 2011.

BICALHO, Lucinéia Maria. As relações interdisciplinares refletidas na literatura brasileira da ciência da informação. 2009. 267 f. Tese (Doutorado em Ciência da Informação) - Escola de Ciência da Informação, Universidade Federal de Minas Gerais, Belo Horizonte, 2009.

BORKO, H. Information Science: what is it? American Documentation, v. 19, n. 1, p. 3- 5, Jan. 1968.

BRAGA, Gilda Maria. Informação, ciência da informação: breves reflexões em três tempos. Ciência da Informação, Brasília, v. 24, n. 1, p. 84-88, 1995.

BRIGGS, Asa; MICHAUD, Guy. Problèmes et solutions. In: OCDE. Problemes d'enseignement et de recherche dans les universités. Paris: OCDE, 1972. p. $191-265$.

CROSLAND, Dorothy M. Georgia Tech and the NSF study grant for training personnel for scientific and technical libraries. Special Library, p. 590-594, dec. 1962. 
FAZENDA, Ivani Catarina Arantes. Integração e interdisciplinaridade no ensino brasileiro: efetividade ou ideologia. 6. ed. São Paulo: Edições Loyola, 2011.

FERNANDES, Wesley Rodrigo. Desvendando as relações de outras disciplinas com a ciência da informação: um estudo comparativo entre a pesquisa nacional e internacional. 2019. 361 f. Tese (Doutorado em Gestão e Organização do Conhecimento) - Escola de Ciência da Informação, Universidade Federal de Minas Gerais, Belo Horizonte, 2019.

GOMES, Henriette Ferreira. Interdisciplinaridade e Ciência da Informação: de característica a critério delineador de seu núcleo principal. DataGramaZero, Rio de Janeiro, v. 2, n. 4, 2001.

GUSDORF, Georges. Conhecimento interdisciplinar. In: POMBO, Olga; GUIMARAES, Henrique Manuel; LEVY, Teresa (orgs.). Interdisciplinaridade: antologia. Porto: Campo das Letras, 2006a, p. 37-58.

GUSDORF, Georges. "Interdisciplinaire (connaissance)", verbete da Enciclopaedia Universalis. apud JAPIASSU, Hilton. Interdisciplinaridade e patologia do saber. Rio de Janeiro: Imago, 1976.

HAYASHI, Maria Cristina Piumbato Innocentini et al. História da educação brasileira: a produção científica na biblioteca eletrônica SciELO. Educação \& Sociedade, Campinas, v. 29, n. 102, p. 181-211, 2008.

HIGINO, Anderson Fabian Ferreira; DUMONT, Lígia Maria Moreira. Ciência da Informação e interdisciplinaridade no contexto brasileiro: um estudo qualiquantitativo com foco no ENANCIB. In: ENCONTRO NACIONAL DE PESQUISA EM CIÊNCIA DA INFORMAÇÃO, 13., 2012, Rio de Janeiro. Anais [...]. Rio de Janeiro: Fiocruz, 2012. 1 CD-ROM.

JANTSCH, Erich. Vers línterdisciplinarité et la transdiciplinarité das dans l'enseignement et l'innovation. In: OCDE. Problemes d'enseignement et de recherche dans les universités. Paris: OCDE, 1972. p. 98-124.

JAPIASSU, Hilton. Interdisciplinaridade e patologia do saber. Rio de Janeiro: Imago, 1976.

MORAES, Marcos; CARELLI, Ana Esmeralda. A interdisciplinaridade na ciência da informação pela perspectiva da análise de citações. Em Questão, Porto Alegre, v. 22, n. 1, p. 137-160, 2016.

NICOLESCU, Basarab. 0 manifesto da transdisciplinaridade. 2 ed. São Paulo: Triom, 2001.

NUNES, Lucilene. Epistemologia e Ciência da Informação: um estudo das comunicações do GT1 do ENANCIB. 2009. 132 f. Dissertação (Mestrado em 
Ciência da Informação) - Universidade Estadual Paulista "Júlio De Mesquita

Filho" Faculdade de Filosofia e Ciências, Marília, 2009.

PAIM, Isis et al. Interdisciplinaridade na ciência da informação: início de um diálogo. Perspectivas em Ciência da Informação, Belo Horizonte, v. 6, n. 1, p. 19-26, jan./jun. 2001.

PIAGET, Jean. L'epistemologie dês relations interdisciplinaires. In: OCDE. Problemes d'enseignement et de recherche dans les universités. Paris: OCDE, 1972. p. 131-144.

PINHEIRO, Lena Vânia Ribeiro. A ciência da Informação: desdobramentos disciplinares, interdisciplinares e transdisciplinares. In: GONZÀLES DE GÓMEZ, M. N.; ORRICO, E. G. D. (Org.). Políticas de memória e informação: reflexos na organização do conhecimento. Natal: Editora UFRN, 2006. p.111-141.

PINHEIRO, Lena Vania Ribeiro; LOUREIRO, José Mauro Mattheus. Traçados e limites da Ciência da Informação. Ciência da Informação, Brasília, v.24, n.1, p.42-53, jan./jul.1995.

POMBO, Olga. Epistemologia da interdisciplinaridade. Ideação: Revista do Centro de Educação e Letras da UNIOLESTE, Foz do Iguaçu, v. 10, n.1, p. 940, 2008.

POMBO, Olga. Interdisciplinaridade: ambições e limites. Lisboa: Antropos, 2004.

REPKO, Allen F. Defining Interdisciplinary Studies. In: REPKO, Allen F. Interdisciplinary Research: process and theory. Los Angeles: Sage, 2008. p. 3-26.

REPKO, Allen F. Defining Interdisciplinary Studies. In: REPKO, Allen F. Interdisciplinary Research: Process and Theory. 2. ed. Los Angeles: Sage, 2012.

SANTANA, Glessa Heryka Celestino de. A Ciência da Informação e sua consolidação em face da interdisciplinaridade. Encontros Bibli: revista eletrônica de biblioteconomia e ciência da informação, v. 17, n. 35, p. 1-26, 2012.

SANTOS NETO, João Arlindo dos et al. Interdisciplinaridade no contexto da Ciência da Informação: correntes e questionamentos. Em Questão, Porto Alegre, v. 23, n. 1, p. 9-35, jan./abr. 2017.

SARACEVIC, Tefko. Ciência da informação: origem, evolução e relações. Perspectivas em Ciência da Informação, Belo Horizonte, v. 1, n. 1, p. 41-62, jan./jun. 1996 
SHERA, J. H.; CLEVELAND, D. B. History and foundations of Information Science. Annual Review of Information Science and Technology, v. 12, p. 249-275, 1977.

SOUZA, Edivanio Duarte de. A ciência da informação: fundamentos epistemológico-discursivos do campo científico e do objeto de estudo. Maceió: EDUFAL, 2015.

SOUZA, Edivanio Duarte de. A epistemologia interdisciplinar na ciência da informação: dos indícios aos efeitos de sentido na consolidação do campo disciplinar. 2011. 346 f. Tese (Doutorado em Ciência da Informação)-Escola de Ciência da Informação, Universidade Federal de Minas Gerais, Belo Horizonte, 2011.

TARGINO, Maria das Graças. A interdisciplinaridade da Ciência da Informação como área de pesquisa. Informação \& Sociedade: estudos, João Pessoa, v. 5, n. 1, p. 12-17, jan./dez. 1995.

TAYLOR, Robert S. Professional aspectos of information science and technology. Annual Review of Information Science and Technology, v. 1, p. 15-40, 1966.

ZINS, Chaim. Classification schemes of Information Science: twenty-eight scholars map the field. Journal of the American Society for Information Science and Technology, v. 58, n. 5, p. 645-672, 2007a.

ZINS, Chaim. Conceptions of information science. Journal of the American Society for Information Science and Technology, v. 58, n. 3, p. 335-350, 2007b.

ZINS, Chaim. Conceptual approaches for defining 'data', 'information', and 'knowledge'. Journal of the American Society for Information Science and Technology, v. 58, n. 4, p. 479-493, 2007c.

ZINS, Chaim. Knowledge map of Information Science. Journal of the American Society for Information Science and Technology, v. 58, n. 4, p. 526-535, 2007d.

\title{
UNVEILING THE RELATIONSHIPS OF OTHER DISCIPLINES WITH THE SCIENTIFIC PRODUCTION OF BRAZILIAN INFORMATION SCIENCE
}

\begin{abstract}
Introduction: Although information science is labeled as an interdisciplinary science, the literature demonstrates that there is no consensus in the scientific community on this issue. Objective: investigate in the scientific literature the use of knowledge produced by Brazilian information science by researchers from other scientific areas and determine
\end{abstract}


the type of relationship (multi, inter or transdisciplinary) established between other disciplines and information science. Methodology: The research was conducted in two stages. The data analyzed in the first stage came from an analysis of citations to Brazilian information science researches published between 1997 and 2016. SciELO, a digital library of scientific journals from Spanish and Portuguese speaking countries was used to gather this data. In the second stage, a quantitative analysis was performed in a convenience non-probabilistic sample of $15 \%$ of the citations of other disciplines to works from Brazilian information science indentified in the first stage. Furthermore, in the sample used in the second stage, for works of citations that showed properties indicating that research was built on the basis of an interdisciplinary relationship, a qualitative analysis was performed to determine the type of disciplinary relationship established in these works. Results: Should be highlighted that there was a growing trend of citations of information science papers by other scientific areas. It was also verified that the other areas of knowledge use the scientific knowledge produced by the national information science. Conclusions: It was found that Brazilian information science seems to have advanced theoretically and methodologically in the last 20 years. There was also an indication of the occurrence of a potential interdisciplinary relationship of other disciplines with Brazilian information science. However, this potential interdisciplinary relationship was not confirmed by the quantitative and qualitative analysis performed in the second stage of the research.

Descriptors: Information Science. Interdisciplinarity. Multidisciplinarity. Transdisciplinarity. Epistemology of information science.

\title{
REVELANDO LAS RELACIONES DE OTRAS DISCIPLINAS CON LA PRODUCCIÓN CIENTÍFICA DE LA CIENCIA DE LA INFORMACIÓN BRASILEÑA
}

\begin{abstract}
RESUMEN
Introducción: aunque la ciencia de la información sea etiquetada como una ciencia interdisciplinaria, la literatura demuestra que no hay consenso en la comunidad científica sobre este tema. Objetivos: investigar en la literatura científica el uso del conocimiento producido por la ciencia nacional de la información por investigadores de otras áreas científicas y determinar el tipo de relación (multi, inter o transdisciplinaria) establecida entre otras disciplinas y la ciencias de la información. Metodología: la investigación se realizó en dos etapas. Los datos analizados en la primera etapa, provienen de unos análisis de citas a trabajos brasileños de ciencias de la información publicados entre 1997 y 2016, presentes en SciELO. En la segunda etapa, se realizó un análisis cuantitativo en una muestra no probabilística para la conveniencia del $15 \%$ de las citas de otras disciplinas a trabajos de la ciencia de la información nacional identificados en la primera etapa. Aún en la muestra utilizada en la segunda etapa, para los trabajos de las citas que mostraron propiedades que indican que fueron construidos sobre la base de una relación interdisciplinaria, se realizó un análisis cualitativo para determinar el tipo de relación disciplinar establecida en estas obras. Resultados: cabe destacar que hubo una tendencia creciente en las citas de trabajos nacionales en el área de la ciencia de la información por otras áreas del conocimiento científico. También se verificó que las otras áreas de conocimiento utilizan el conocimiento científico producido por la ciencia de la información nacional. Conclusiones: se encontró que la ciencia de la información nacional parece haber avanzado teórica y metodológicamente de manera sistemática
\end{abstract}


en los últimos 20 años. También hubo una indicación de la ocurrencia de una posible relación interdisciplinaria entre otras disciplinas y la ciencia de la información brasileña. Sin embargo, esta posible relación interdisciplinaria no fue confirmada por el análisis cuantitativo y cualitativo realizado en la segunda etapa de la investigación.

Descriptores: Ciencia de la información. Interdisciplinariedad. Multidisciplinariedad. Transdisciplinariedad. Epistemología de la ciencia de la informa.

Recebido em: 07.05.2020

Aceito em: 26.10 .2020 